\title{
44574 - PILOT STUDY TO DETERMINE SEVOFLURANE DOSING DURING CARDIO-PULMONARY BYPASS USING BIS MONITORING
}

\author{
Jean-François Olivier, Montreal General Hospital, Montreal, QC, Canada; \\ Julien Rhéaume, University of Montreal; \\ David Bracco, Montreal General Hospital; \\ Thomas Hemmerling, Montreal General Hospital;
}

INTRODUCTION: Volatile anesthetics provide myocardial protection during cardiac surgery. Sevoflurane has gained popularity in cardiac surgery because of its rapid elimination thus allowing fast tracking anesthesia. Titration of sevoflurane dosing during cardiopulmonary bypass (CPB) is important to avoid awareness and provide hemodynamic stability. In this pilot study, we titrated sevoflurane during cardio-pulmonary bypass using bispectral index monitoring (BIS). The aim of this study was to measure the MAC of sevoflurane during normothermic CPB.

METHODS: Local IRB approval was obtained for this study. 20 patients scheduled for elective cardiac surgery using normothermic CPB were enrolled. Anesthesia was induced using propofol $1-1.5 \mathrm{mg} / \mathrm{kg}$, fentanyl $3-5 \mu \mathrm{g} / \mathrm{kg}$ and rocuronium $0.6 \mathrm{mg} / \mathrm{kg}$. Intraoperative analgesia was achieved using high thoracic epidural analgesia with bupivacaine $0.125 \%$ at $10 \mathrm{ml} / \mathrm{h}$. Anesthesia was maintained using sevoflurane throughout surgery; during $\mathrm{CPB}$, sevoflurane was administered through the oxygenator to maintain a BIS of 40-55. Exhausted gases from the oxygenator were sampled by an anesthesia gas analyzer. Every min, BIS, the concentration of sevoflurane, blood pressure and central temperature were recorded and averaged by blocks of 5 minutes. Data are presented as means $( \pm \mathrm{SD})$.

RESULTS: 11 men and 9 women, age $69 \pm 12$ yrs, were observed during a mean CPB time of 70 \pm 26 minutes. Adequate levels of anesthesia could be provided to all patients and no signs of awareness were recorded. Blood pressure was maintained between 60 and $80 \mathrm{mmHg}$. To maintain BIS between 40 and 60, the mean expired sevoflurane required was $1.36 \pm 0.71 \%$ for a mean BIS of $47.5 \pm 13.4$. There was a negative correlation between BIS and expired Sevoflurane.

DISCUSSION: This is the first study that uses BIS to titrate sevoflurane administration during CPB. Sevoflurane through the oxygenator provides adequate anesthesia during CPB. During normothermic cardiopulmonary bypass, the MAC for sevoflurane is $1.36 \%$. 


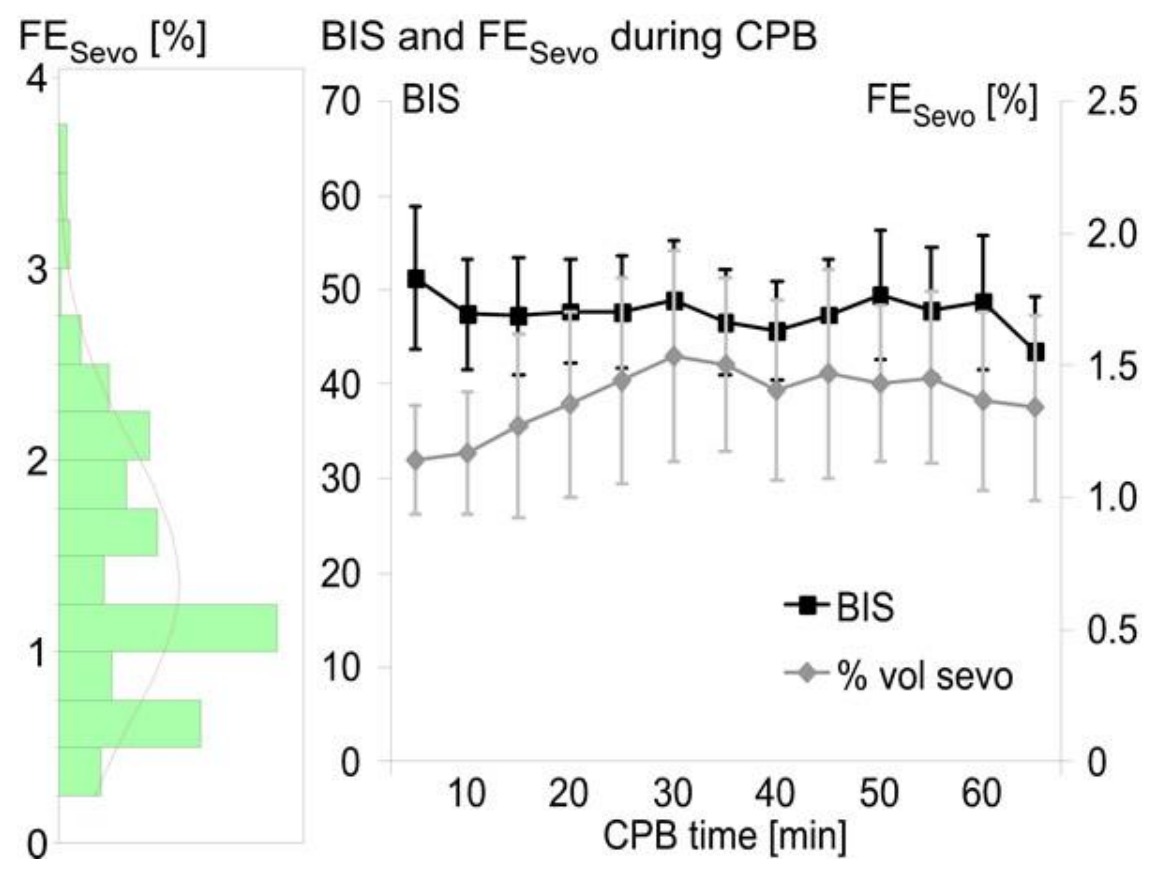

